\title{
Targeting the neurological comorbidities of multiple sclerosis: the beneficial effects of VIP and PACAP neuropeptides
}

\author{
Margo I. Jansen ${ }^{1, \dagger}$, Sarah Thomas Broome ${ }^{1, \dagger}$, Alessandro Castorina ${ }^{1, *}$ \\ ${ }^{1}$ Laboratory of Cellular and Molecular Neuroscience (LCMN), School of Life Sciences, Faculty of Science, University of Technology Sydney, 2007 Sydney, New \\ South Wales, Australia
}

*Correspondence: Alessandro.Castorina@uts.edu.au (Alessandro Castorina)

${ }^{\dagger}$ These authors contributed equally.

\section{DOI:10.31083/j.jin2101033}

This is an open access article under the CC BY 4.0 license (https://creativecommons.org/licenses/by/4.0/).

Submitted: 28 July 2021 Revised: 16 August 2021 Accepted: 13 September 2021 Published: 28 January 2022

Vasoactive intestinal peptide (VIP) and pituitary adenylate cyclaseactivating polypeptide (PACAP) are two widely expressed neuropeptides with important immunomodulatory and neuroprotective properties in the central nervous system (CNS). Both VIP and PACAP have been implicated in several neurological diseases and have shown favourable effects in different animal models of multiple sclerosis (MS). MS is a chronic inflammatory and neurodegenerative disease of the CNS affecting over 2.5 million people worldwide. The disease is characterised by extensive neuroinflammation, demyelination and axonal loss. Currently, there is no cure for MS, with treatment options only displaying partial efficacy. Importantly, epidemiological studies in the MS population have demonstrated that there is a high incidence of neurological and psychological comorbidities such as depression, anxiety, epilepsy and stroke among afflicted people. Hence, given the widespread protective effects of the VIP/PACAP system in the CNS, this review will aim at exploring the beneficial roles of VIP and PACAP in ameliorating some of the most common neurological comorbidities associated with MS. The final scope of the review is to put more emphasis on how targeting the VIP/PACAP system may be an effective therapeutic strategy to modify MS disease course and its associated comorbidities.

\section{Keywords}

Multiple sclerosis; Vasoactive intestinal peptide; Pituitary adenylate cyclaseactivating peptide; Comorbidities; Stroke; Epilepsy; Depression; Anxiety; Schizophrenia; Migraine

\section{Introduction}

\subsection{Neuropeptides}

Over the last couple of decades, general knowledge on the biological role of neuropeptides in the central nervous system (CNS) has increased substantially. Currently, more than a hundred different neuropeptides have been described in the CNS, most of which are involved in the modulation of different brain functions [1-5]. Neuropeptides are small, amino acid-based molecules that can influence neuronal activity, neuro-immune responses and whose dysregulations have been implicated in the pathogenesis of several mental illnesses such as Alzheimer's or Parkinson's disease, depression, anxiety, stroke, migraines, epilepsy and multiple sclerosis [6-15].
It has become increasingly clear that certain neuropeptides such as neuropeptide Y (NPY), somatostatin, calcitonin gene-related peptide (CGRP), vasoactive intestinal peptide (VIP) and pituitary adenylate cyclase-activating polypeptide (PACAP) exert anti-inflammatory effects in the CNS [16]. This has resulted in research focusing on these neuropeptides as potential therapeutic targets for the treatment of neuroinflammatory diseases [17-21].

\subsection{PACAP and VIP}

The neuropeptides pituitary adenylate cyclase-activating polypeptide (PACAP) and vasoactive intestinal peptide (VIP) are widely distributed throughout the CNS and the peripheral nervous system (PNS) and are involved in neuroprotection and immunomodulation [22-27]. The activities of PACAP and VIP are mediated by three $G$ protein-coupled receptors (GPCRs), namely PAC1, VPAC1 and VPAC2 [28] (Fig. 1).

PACAP binds with high affinity to both PAC1, VPAC1 and VPAC2 receptors and its activity is believed to be predominantly neuroprotective [29-31]. For example, PACAP can prevent neuronal cell death after ischemia [32] and can promote axonal regeneration after spinal cord injury [33]. In contrast, VIP binds less efficiently to PAC1 receptors, whereas its exhibits similar high affinities for VPAC1 and VPAC2 receptors as PACAP [34]. The latter two receptors' activities are thought to be mainly associated with immune modulatory roles in the CNS as well as in peripheral organs [35-37]. Given VIP binding preference towards VPAC receptor subtypes, this peptide has emerged as a potential antiinflammatory target to treat multiple sclerosis (MS) and perhaps, other inflammatory diseases [38, 39]. For example, in human rheumatoid arthritis (RA), VIP treatment downregulated chemokines production and interleukin-6 (IL-6) and decreased the levels of other pro-inflammatory mediators in RA patients [40]. Additionally, a single intracerebroventricular injection of VIP was able to attenuate microglial activation and prevented neurodegeneration in animal models of Parkinson's disease [41]. 


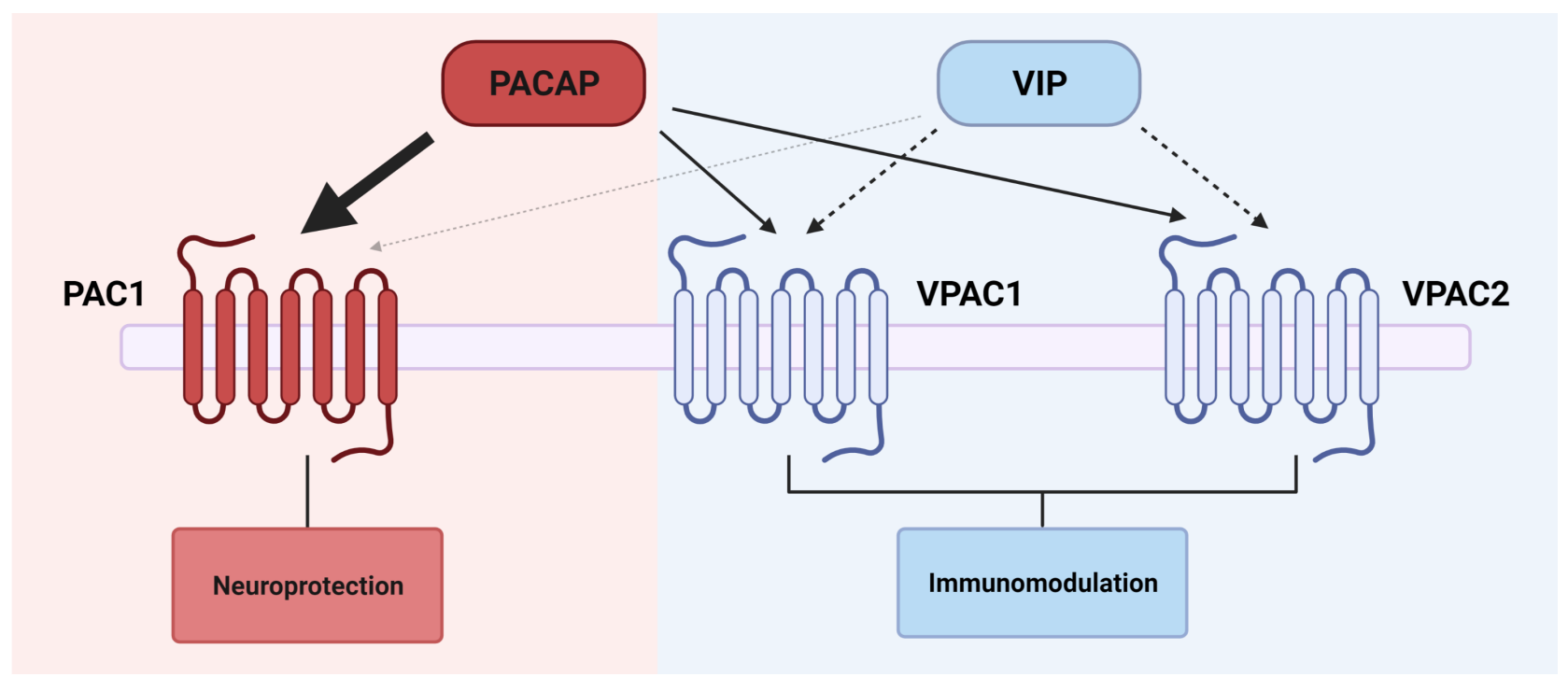

Fig. 1. PACAP and VIP and their downstream effects. A schematic overview of the binding of VIP and PACAP to the PAC1, VPAC1 and VPAC2 receptor with its main down-stream effects.

\subsection{VIP/PACAP system in multiple sclerosis 1.3.1 Multiple sclerosis}

MS is a chronic neuroinflammatory disease of the CNS that is characterised by episodes of demyelination within the CNS, with consequent axonal loss and gliosis. Both genetic vulnerability and/or exposure to certain environmental pollutants or unhealthy life styles are considered risk factors for disease development $[42,43]$. The prevalence of MS has been increasing over the last decade with currently approximately 2.8 million people suffering from the disease worldwide [44].

There is a clear involvement of the immune system in MS, with the infiltration of auto-reactive T cells into the CNS believed to be a major pathophysiological event in disease aetiology [45]. Moreover, B cells, natural killer (NK) cells, astrocytes and microglia have also been shown to exacerbate CNS inflammation, thus playing a role in both disease onset and progression [46-48]. In fact, the heightened inflammatory state of the CNS observed in MS is believed to exacerbate the ongoing loss of myelin and axonal degeneration caused by a myelin-targeted autoimmunity [49]. A brief overview of current knowledge on the role of the VIP/PACAP system in neuroinflammation and myelination in MS is highlighted below.

\subsubsection{VIP/PACAP and neuroinflammation in multiple sclerosis}

Given the known neuroprotective and immunomodulatory roles of the VIP/PACAP system in the body, these endogenous neuropeptides have been thoroughly investigated in MS. In MS patients, it was found that both PACAP and VIP levels are reduced in the cerebrospinal fluid [50]. Moreover, using global and conditional knockouts for VIP, PACAP and their receptors, Waschek and colleagues have been able to dissect many of the neuroprotective and immunomodulatory actions elicited by these peptides in acute monophasic $\mathrm{MOG}_{33-35}$ experimental autoimmune encephalomyelitis
(EAE) models, a well-established mouse model of MS [5154]. These authors revealed that mice lacking PACAP or VPAC2 displayed more severe and prolonged disease than wild type controls while VIP or VPAC1 knockout mice showed EAE resistance [53-55].

When examining the effects of VIP and PACAP at a cellular level in MS models, a clear immunomodulatory influence can be observed. Extensive research has focused on the effect of PACAP and VIP on T-cell function, but additional effects have been reported on other immune cell populations. VIP and PACAP have been shown to regulate Th1 and Th17 profiles, triggering the shift towards anti-inflammatory phenotypes, whilst also assisting in the recruitment of antiinflammatory Th2 and Treg cells $[17,39,51-53,56,57]$. Additionally, PACAP ${ }^{-/-}$and VPAC2 ${ }^{-/-}$mice subjected to $\mathrm{MOG}_{33-35}$ induced EAE showed increased immune cell infiltration in the CNS, whereas reduced infiltration was seen in $\mathrm{VIP}^{-/-}$and VPAC1 ${ }^{-/-}$mice $[51,53-55]$. In vitro analyses also determined that PACAP or VIP treatment in cultured cells and in EAE models resulted in reduced levels of pro-inflammatory cytokines, chemokines, chemokine receptors and inducible nitric oxide synthase (iNOS) produced by T-cells, macrophages and microglia [39, 58-63]. This could potentially contribute to the observed neuroprotective effect, as a reduced inflammatory microenvironment is likely to promote the upregulation of cell survival genes by neurons and glia [64]. Moreover, PACAP treatment was also shown to suppress the function of antigen presenting cells in the EAE model, which is an important mediator of T-cell differentiation $[56,65]$.

Taken together, these findings corroborate the idea that VIP and PACAP play a critical role in the modulation of the inflammatory response of the CNS both in vivo and in vitro. However, given the diversified activities of either peptides in 
several pathological domains of the disease, there is the need for additional research to further breakdown the differential effects of these peptides and their receptors on the immune system and the CNS.

\subsubsection{VIP/PACAP and myelination}

In addition to the established immunomodulatory and neuroprotective effects of VIP and PACAP in the nervous system, there is evidence to indicate that both neuropeptides may be critically involved in regulating certain aspects of oligodendrocyte and Schwann cell proliferation and maturation $[66,67]$.

Oligodendrocytes are the myelin producing cells of the CNS and the main cell-type affected in MS. PACAP is a known stimulator of oligodendrocyte progenitor cell proliferation, although it delays oligodendrocytes maturation in vitro $[68,69]$. These findings have been substantiated using knockout mice, where PACAP-deficiency anticipated CNS myelination, although within a limited time window [70]. As far as these data may appear counterintuitive, the authors suggested that the physiological and transient inhibitory role of endogenous PACAP on myelination may serve to reduce the secretion of factors that impede axonal development and synapse formation by myelinating glia, and therefore, promote neuronal outgrowth over myelination, at least during the earliest stages of CNS development, when the former process should be prioritised. In this scenario, endogenous PACAP acts as a master regulator of CNS maturation. Nonetheless, additional investigations are warranted to clarify the exact involvement of PACAP/VIP receptors in relationship to CNS myelination at different developmental ages and in adulthood, as it is possible that a developmentally regulated expression of PACAP/VIP receptors or specific receptor isoforms may be at the basis of a diversified activity of the peptides, a mechanism already proposed for cortical development [71].

In Schwann cells, the myelin-producing cells of the PNS, PACAP and VIP activities are more obvious. In fact, as shown in PACAP knockout mice, genetic ablation of the $P A C A P$ gene results in impaired axon regeneration upon $\mathrm{fa}-$ cial nerve injury [72]. In vitro, PACAP or VIP treatment of cultured Schwann cells induces the up-regulation of myelinrelated proteins, suggesting that PACAP may enhance PNS myelination [73-75]. VIP, on the other hand, is believed to play a more differentiating role in oligodendrocyte progenitor cells in the CNS [67]. VIP/VPAC1 signaling was shown to reduce the severity of ibotenate-induced white matter lesions under inflammatory conditions [76]. Moreover, there are some indications of a myelin deficit in the CNS of VIPdeficient mice, although more in-depth studies are needed before this can be confirmed [67]. In the PNS, VIP administration in the proximity of transected nerves promoted early myelination and re-myelination of damaged nerves, and it induced the expression of myelin-related proteins by Schwann cells [77].
Thus, there are indications of a differential effect of VIP and PACAP in regulating CNS and PNS myelination. Although it is beyond the scope of this review to further dive into the details of the role of VIP and PACAP in myelin development, there are excellent reviews $[67,73]$ summarizing some of the current knowledge in the field.

\subsection{Multiple sclerosis and associated comorbidities}

Recent studies have demonstrated both a higher incidence and prevalence of comorbidities in MS patients compared with the healthy population $[78,79]$. MS comorbidities often appear in people suffering from concurrent vascular and/or metabolic diseases, as well as certain neurological and psychiatric disorders [80-84]. Epidemiological studies in MS patients have demonstrated that afflicted people also have a higher chance of developing epilepsy [83], migraines [84] , as well as affective/emotional disturbances such as depression or anxiety [79]. In view of the comorbidities often seen in MS patients and the critical role of neuropeptides in many pathological domains of these comorbidities, exploring the mechanisms and the extent at which both PACAP and VIP peptides can contribute to ameliorate the comorbidities of MS is becoming a hot topic. For this purpose, this review will summarise literature on the role of neuropeptides, focussing on the role of VIP and PACAP in the neurological comorbidities of MS, and how these neuropeptides could contribute to improve the clinical presentation of MS and disease course.

\section{The role of PACAP and VIP neuropeptides in the comorbidities of MS}

\subsection{Depression, anxiety and bipolar disorder}

MS is a devastating disease that comes with physical as well as psychological hardship, which may ultimately lead to the development of mood disorders or facilitate its onset in vulnerable people. One of the most prevalent comorbidities seen in MS patients is depression (23.7\%), followed by anxiety (21.9\%) and bipolar disorder (BD; 5.83\%) [79]. Interestingly, these disorders are all associated with neurochemical evidence of CNS inflammation, supporting a pathological link with MS [12, 85-88]. Moreover, depression, anxiety and $\mathrm{BD}$ are all known to be influenced and triggered by stress, a risk factor able to also affect oligodendrocyte's health [89-93]. Here, the role of PACAP and VIP in depression, anxiety and $\mathrm{BD}$ is highlighted.

Several neuropeptides such as NPY, somatostatin, galanin and orexin, at different extents, have been implicated in the pathology of affective disorders and have been suggested as potential therapeutic targets [21, 94-101]. The VIP/PACAP system has also been implicated with depression and anxiety, although there are some conflicting findings. In some studies using PACAP-deficient mice, $P A C A P$ gene ablation increased depressive-like and anxiety-like behavior under stress conditions [102-104], whereas in a study by Lehmann and colleagues it was found that $\mathrm{PACAP}^{-/-}$mice had reduced anxiety and did not develop depressive-like behaviors [105]. However, this study used social defeat to trigger chronic 
stress whereas the other studies either used naïve mice or mice exposed to a milder form of stress. Thus, PACAP ${ }^{-/-}$ mice might exhibit a whole spectrum of behavioral disorders, depending on the initial source of stress, type and duration. In a clinical study, VIP serum levels negatively correlated with depression and anxiety state and positively correlated with brain volume of the left amygdala [106]. Similarly, decreased serum levels of VIP were detected in a rat depression model [107]. Moreover, single nucleotide polymorphisms (SNPs) in the VIPR2 gene and VIP gene were found to be associated with unipolar major depression and BD, respectively [108]. In addition, a VIP injection into the CA1 region of the hippocampus of rats showing anxiety-like behaviors attenuated the symptoms [109], although, for unexplained reasons, VIP antagonist was not able to abolish VIPmediated behavioral improvements.

Corticosterone, one of the hormones produced by the adrenal gland as part of the hypothalamic-pituitary-adrenal axis (HPA-axis), is known to play a critical role in the development of depression, anxiety and bipolar disorder [92, 110, 111]. Under stress conditions, PACAP-deficient mice exhibited an attenuated corticosterone response, which occurred irrespectively of the development of depressive-like behaviors [105, 112]. Moreover, PACAP injections into the amygdala and bed nucleus of the stria terminalis (BNST) have been found to reliably increase corticosterone levels and anxietylike behaviors in rodents [113-115]. Interestingly, under chronic stress conditions there was a region-specific increase of PACAP and PAC1, but not VIP and VPAC1-2 levels in the BNST [116]. VIP has also been implicated in the control of glucocorticoid hormones release, although in a work focused on studying its effects in relationship to circadian rhythmicity [117]. Thus, there appears to be a link between PACAP, stress and the HPA axis, which could be relevant for the development of certain affective disorders.

In summary, the VIP/PACAP system appears to be a key player in the modulation of mood and other affective disturbances. Each peptide exerts intrinsic regulatory functions in brain homeostasis and it is not surprising that dysfunctional regulation of PACAP or VIP in specific brain regions or cell populations may be critical for the development of conditions such as depression, anxiety and bipolar disorder. Future research is warranted to explore if targeting this neuropeptide system can be used as an effective therapeutic strategy to treat mood disorders.

\subsection{Psychotic disorders-focus on schizophrenia}

Psychotic disorders encompass a broad range of mental illnesses such as schizophrenia, affective psychosis, delirium and drug-induced psychosis. Approximately 2-4\% of MS patients have reported to experience psychotic episodes at some point during the course of the disease, which is a considerably higher rate than in the general population [118]. In line with MS pathology, neuroinflammation and increased oxidative stress events in the CNS are pathogenic events that are associated with the occurrence of certain psychotic disorders

\section{$[119,120]$}

Several neuropeptides have shown to activate signalling pathways that are implicated in the genesis of psychosis. Clear associations have been found between schizophrenia and neuropeptide $\mathrm{Y}$, neurotensin, somatostatin and oxytocin and the number of psychotic episodes (reviewed in $[121,122])$. Moreover, a genetic link between neuregulin1 (NRG1), cholecystokinin A and schizophrenia has been described [123-127]. Similarly, genetic polymorphisms of genes encoding PACAP peptide or its receptors have also been correlated with schizophrenia [128-132], although for the former gene target (PACAP gene, aka Adcyap1), a replication study failed to reproduce the same findings [133].

There are certain indications that neuroinflammation can lead to the development of schizophrenia and psychotic episodes. In schizophrenia and first-time psychosis patients, studies have reported increased levels of pro-inflammatory cytokines and decreased levels of the anti-inflammatory cytokine IL-2 in the CNS [134, 135]. Additionally, increased microglia activation has been observed in recentonset schizophrenic patients [136, 137]. However, since no comprehensive animal model exists for psychiatric diseases, reliable strategies to study neuroinflammation at a molecular level in psychiatric illnesses remains a daunting task. Furthermore, since neuroinflammation in schizophrenia is a relatively novel concept, the exact mechanisms through which it could contribute to disease aetiology remain uncertain. However, it would be interesting to explore if the antiinflammatory activities of the VIP/PACAP system could potentially attenuate the CNS inflammation seen in people with psychotic disorders.

There is a leading hypothesis featuring schizophrenia as a neurodevelopmental disorder [138, 139]. In post mortem brain tissue from schizophrenic patients, the pool of neural stem cells (NSC) is reduced, suggesting decreased NSC proliferative activity [140]. Moreover, schizophrenia is characterised by abnormal connectivity among brain regions and axonal abnormalities [141-143]. A noteworthy link between brain development, schizophrenia and white matter can be seen for NRG1. NRG1 signals through disruptedin-schizophrenia 1 (DISC1) and interestingly, PACAP has been found to affect DISC1 signalling as well [144]. In addition, both NRG1 and DISC1 are involved in neuronal migration, axon ensheathment and oligodendrocyte maturation [145, 146], suggesting a role for PACAP in modulating NRG1-mediated activities. Moreover, PACAP, PAC1 and DISC1 are known to be essential components of the cellular machinery that regulates neurite outgrowth [144, 147, 148]. PACAP stimulated NSC proliferation in mice and prevented the reduction of NSCs in a ketamine-induced schizophrenialike mouse model via PAC1 receptor activation [149, 150].

Taken together, these data suggest that PACAP (and perhaps other PACAP/VIP receptor agonists) could aid in the treatment of schizophrenia. Based on the reported promitotic activities of PACAP in NSCs, it is reasonable to hy- 
pothesise that PACAP treatment could aid in replenishing the depleted pool of NSCs in the brain of schizophrenic patients, hence promoting neurogenesis. Additionally, it could reduce the chronic CNS inflammation that seems to also contribute to the development of psychotic disorders. Whilst additional investigations into this topic are still needed, there is already some indication that the beneficial actions of certain neuroleptic drugs can occur by mechanisms that involve restoring the dysfunctional VIP/PACAP signalling in the brain [151].

\subsection{Epilepsy}

Epilepsy is a chronic neurological disorder that is characterised by recurring and unprovoked seizures [152]. Seizures occur when the balance between excitatory and inhibitory signals in the brain is disrupted [152]. Epilepsy is one of the most common neurological disorders that is disproportionately prevalent in MS patients compared to the general population [153]. It has been reported that the prevalence of epilepsy is six times higher in MS patients than in the healthy population [154]. This is not surprising, as both lesions, inflammation and neurotransmitter imbalances within the CNS of people with MS may trigger such disabling ailment, with evidence also suggesting that the frequency of seizures tends to increase as the disease progresses [155].

As mentioned, an imbalance in neuronal activity is a critical neurochemical feature of seizure episodes [152]. It is welldocumented that neuropeptides can contribute to reset this imbalance, including PACAP and VIP $[156,157]$. Despite the emerging evidence, to date only one neuropeptide-based hormone, adrenocorticotropic hormone (ACTH), is currently being tested in clinical trials for the treatment of seizures in a rare disease that affects infants (West syndrome), whereas investigations on the efficacy of other neuropeptides in epilepsy has been limited to preclinical studies $[152,158]$.

PACAP and VIP are released during high neuronal firing activity $[159,160]$. VIP exerts an overall excitatory effect on synaptic transmission, which is mediated by VPAC1 and VPAC2 receptors [161, 162]. In hippocampal surgical samples of patients suffering from human temporal lobe epilepsy, both VPAC1 and VPAC2 receptors were shown to be upregulated [15] and up-regulation of VPAC receptor subtypes has been associated with increased neuronal survival [161]. These data support the idea that hippocampal VPAC receptors are increased as a homeostatic mechanism to prevent excessive neuronal damage/death caused by epileptic episodes.

Research into the role of PACAP in epilepsy has been centred on its ability to modulate microglia and glutamate transmission [163-165]. The expression of PACAP increases after kainic acid-induced seizures in rats, with many suggesting that this seizure-induced increase in PACAP may help to reduce excitotoxicity and promote overall neuroprotection to protect the CNS from damage [163]. Specifically, PACAP acts on microglia to promote the release of anti-inflammatory factors that polarise microglia towards an anti-inflammatory phenotype, whilst concurrently increasing the expression of glutamate transporters that promote glutamate re-uptake, resulting in two parallel protective mechanisms [166, 167].

Magnetic resonance imaging and pathological studies have proposed that cortical inflammation, demyelination and grey matter damage in MS patients may be responsible for the onset and development of epileptic seizures [155]. However, epilepsy is an active process, so it is difficult to determine if any aspect of MS pathology may specifically promote or trigger seizure episodes, especially given that MS patients often present with unique pathogenic profiles and distributions of lesion within the CNS. This should be considered as a further incentive to invest more in researching the efficacy of PACAP and VIP as therapeutic targets for epilepsy and MS, as both conditions are often comorbid and targeting these peptides or their receptors may prove to be effective in ameliorating epilepsy associated to MS.

\subsection{Stroke}

Stroke is the leading cause of adult disability, with one in four people globally experiencing a stroke event in their lifetime [168]. Stroke occurs when there is a long-lasting interruption or severe reduction of cerebral blood flow, which triggers a cascade of pathological events including excitotoxicity, oxidative stress, blood brain barrier (BBB) leakage and neuronal cell death [169]. Inflammatory processes, including the autoimmune activities of MS are thought to contribute to endothelial dysfunction and atherosclerosis, which may promote the development of micro- and macro-vascular alterations that culminate in ischaemic or hemorrhagic stroke. As such, it should not be surprising that compared with the general population, people with MS are at increased risk of experiencing a stroke, and if they do, they tend to suffer more severe symptoms [170].

It has been shown that administration of PACAP in animal models of stroke is neuroprotective and causes a reduction of both neurological deficits and the degree of pathological change of the CNS tissue of the ischaemic brain area [26]. There is an increase in inflammation post-stroke $[13,171]$, and PACAP and VIP are well-known anti-inflammatory agents in the CNS [10]. Both peptides are expressed in different types of immune cells, including microglia and astrocytes [37, 172]. Masmoudi-Kouki et al. [173] suggested that the neurotrophic and neuroprotective effects of PACAP and VIP can be partly accounted for by their activities on astrocytes. This idea is supported by the increase in astrocytic PACAP and PAC1 expression immediately following cerebral ischemia [174]. Additionally, exposure of cultured astrocytes to PACAP was found to be capable of up-regulating glutamate uptake via PAC1-mediated signalling, suggesting that the PACAP-PAC1 axis can reduce post-stroke excitotoxicity caused by excessive glutamate release [167].

In a study, treatment with VIP has shown to reduce brain damage and to promote neurogenesis following ischemic injury in the rat brain [175], although it should be highlighted that most of the neuroprotective effects reported for experimental stroke are related to PACAP and not VIP. Indeed, 
studies in PACAP knockout mice suggest that the peptide prevents post-ischemic neuronal cell death $[176,177]$. In animal models of stroke, intranasal administration of PACAP reduced infarct volume and improved functional recovery [178]. Additionally, PACAP-dependent polarisation of microglia towards an anti-inflammatory phenotype resulted in improved functional recovery in mice post-ischemic mice [179].

These studies provide evidence that both PACAP and VIP have potential therapeutic validity for the treatment of stroke, and may find application to aid in the recovery of neuronal injury post-stroke due to their neuroprotective and anti-inflammatory functions.

\subsection{Neuropathic pain}

Neuropathic pain is defined as pain caused by a damage or disease to the somatosensory nervous system [180]. WHO defines MS as one of the main CNS diseases responsible for the development of central neuropathic pain, followed by traumatic causes and other conditions such as spinal cord injury, traumatic brain injury and stroke, with neuropathic pain reported by about $86 \%$ of MS patients [181]. Neuropeptides are key regulators of peripheral nociception and contribute to the mechanisms regulating central sensitisation to pain. In many cases, chronic inflammation, ion channel imbalance and a lack of inhibition in the dorsal horn of the spinal cord partake in maintaining pain sensation [182]. PACAP and VIP are expressed across key anatomical regions/structures that are important in somatosensory processing and the transmission of pain signals [183]. In the PNS, these includes the dorsal root ganglia and peripheral nerves, whereas in the CNS, these peptides are detected in regions that process pain sensation and the associated emotional load, including the thalamus, periaqueductal grey (PAG), parabrachial nucleus and amygdala [22, 184, 185]. Despite the anatomical relevance of PACAP and VIP in neuropathic pain pathways, their distinct roles in the pathophysiology of neuropathic pain remains to be clarified. Studies using PACAP knockout mice have indicated that the peptide plays an excitatory role in pain transmission, as knockout animals do not develop symptoms of neuropathy after a spinal nerve transection, although they retain normal nociceptive responses [186]. These findings have been supported by subsequent studies showing that PACAP up-regulation in the dorsal horn is necessary for spinal sensitation and the development of neuropathic pain [187].

There is evidence to indicate that intrathecal injections of PACAP in mice cause both hyperalgesia and allodynia, two common symptoms of neuropathy [188]. In another study, intrathecal PACAP caused prolonged allodynia that was associated with sustained astrocytic activation [189]. Administration of a PAC1 receptor antagonist inhibited PACAPand nerve injury-induced allodynia, suggesting a crucial role of PACAP-PAC1 interaction in the induction of neuropathic pain [190].

The overlap between pain and inflammatory signalling has been extensively studied and reviewed [189]. Addition- ally, an association between axonal regeneration and pain has been hypothesised, with evidence suggesting that accelerated regeneration may ameliorate pain of nerve origin [182]. PACAP and VIP have well-described roles in promoting axonal regeneration after peripheral nerve injury [34,191]. For example, RNA sequencing data revealed the $A D C Y A P 1$, the gene encoding for the PACAP peptide, was the most differentially expressed gene associated with post-surgical nerve regeneration in patients with carpal tunnel syndrome [192].

Most studies have suggested PACAP has a dominant role in pain pathophysiology compared to VIP. However, Dickinson and collaborators identified distinct regulatory roles of spinal PAC1 and VPAC receptor subtypes in animals with experimentally-induced neuropathy [193], also implicating the VIP-VPAC axis as a further contributor to pain-related regulatory responses. Centrally, PACAP activity in the amygdala has been linked with the emotional expression of pain [185], whereas VIP expression in the PAG has been correlated with the development of co-morbid behaviors in nerveinjured rats [22]. Nonetheless, taken together these data pinpoint the critical role of the PACAP/VIP system in perpetuating both spinal and supraspinal pathways that are involved in the transmission of pain originating from peripheral nerve damage as well as its emotional components. With this in mind, it is conceivable that strategies aimed at blocking PACAP/VIP signaling may be beneficial in mitigating neuropathic pain, a disabling comorbid event associated with MS.

\subsection{Migraine}

Migraine is a complex and debilitating headache disorder that affects one in seven people worldwide [194]. Despite clinically manifesting as recurrent attacks of headache, migraines are associated with a range of symptoms (i.e., nausea, vomiting, and extreme sensitivity to light and sound) and are linked to other conditions like depression, anxiety, sleep disorders, chronic fatigue and cognitive dysfunction [195]. The role of neuropeptides in migraine in an active area of research. The most studied neuropeptide in relation to migraine is CGRP [196]. CGRP administration has been shown to induce migraine-like headaches that are indistinguishable from spontaneous migraine attacks $[197,198]$. This has led to the discovery and use of CGRP antagonists that are effective in treating migraine symptoms [198].

PACAP has been shown to act in a similar way to CGRP, with infusion of PACAP inducing headaches in healthy volunteers [199]. Similarly, plasma levels of CGRP and PACAP are elevated following a migraine attack [200]. Interest in PACAP has a therapeutic target for migraine, stems from the discovery that PACAP-induced migraine did not results in an increase in CGRP, suggesting an alternate route of migraine initiation [201]. Human provocation studies have provided the most robust evidence describing the involvement of PACAP in migraine [201]. Intravenous administration of PACAP produced immediate headache in healthy participants, and delayed migraine in migraine sufferers [203]. Additionally, PACAP induced pronounced dilations of extra- 
cranial arteries [202]. This dilation was further confirmed using magnetic resonance angiography that caused dilation of the middle meningeal artery in participants who reported migraine after PACAP infusion [203].

Despite sharing similar anatomical distribution and vasodilation properties to PACAP, the role of VIP in migraine remains controversial. Previously, it was suggested that VIP was unable to induce migraine [188]. Additionally, Bertels and colleagues, investigated the impact of PACAP and VIP on functional brain connectivity using functional magnetic resonance imaging, and revealed that PACAP, but not VIP, altered connectivity that coincided with the development of migraine in migraine patients [201]. However, recent studies have reported contrasting findings. Pellesi and colleagues, demonstrated that a 2-hour infusion of VIP could induce migraine attacks in $71 \%$ of patients with migraines without aura, similarly to PACAP [204]. They revealed that this induction was caused by dilation of cranial arteries that was mediated by VPAC1 and VPAC2 receptors, contradicting previous notions that migraine was induced via PAC1 receptor activation [204]. This could explain why novel therapeutics targeting PAC1 have had low efficacy in preventing migraine attacks in clinical trials $[201,205,206]$. Therefore, more research is needed to elucidate the specific role of each receptor in migraine induction and maintenance. For example, recent studies have proposed a link between mast cell degranulation and migraine pathology in PACAP-induced attacks, however the receptor mediating this effect has not been identified [207]. Chronic inflammation has been shown to promote the maintenance of pain states. As such, both migraine and neuropathic pain demonstrate the delicate balance of targeting PACAP and VIP in neurological disease due to their pleiotropic functions and global expression.

\section{PACAP and VIP as a broad-spectrum therapy for MS and its associated comorbidities}

The broad beneficial functions of PACAP and VIP in the CNS make them ideal neuroprotective agents, capable of promoting neuronal survival, function and protect neurons against inflammation. These peptides can be useful in a myriad of neurological diseases. In addition, as highlighted in this review, the VIP/PACAP system is clearly implicated in ameliorating several neurological comorbidities associated with MS (Fig. 2).

As highlighted in this review, in MS the VIP/PACAP system has shown to partly counteract autoimmunity. The neuropeptide system causes a shift from autoreactive $\mathrm{T}$ cells to anti-inflammatory state of $\mathrm{T}$-cells by promoting the recruitment of anti-inflammatory Th2 and Treg cells as well as several other immunomodulatory effects (see 1.3.2; reviewed in $[57,208])$. During the active stages of the disease, the MS brain shows signs of white matter inflammation in lesioned areas, which is believed to cause not only myelin damage, but also oligodendrocyte cell loss [49]. As discussed above, an increased inflammatory milieu in the CNS is also a major trigger of the comorbidities associated with MS. Strikingly, CNS white matter pathology has recently been suggested as a contributing factor to disease pathology in schizophrenia, epilepsy and stroke [89, 137, 209-215]. Thus, despite the different clinical presentations and domains of some of the pathologies discussed in this review, the underlying similarities at a molecular level highlight a potential link with a dysfunctional VIP/PACAP system and identify it as a valid target for therapeutic intervention that could span these disorders.

This idea is further substantiated by the overlapping positive effects of the VIP/PACAP system in MS and its comorbidities. The multiple actions of this neuropeptide system could mean that various downstream pathways are likely to be targeted. We predict that targeting this system could potentially ameliorate MS symptoms both by protecting oligodendrocytes, likely through a reduction of the proinflammatory CNS microenvironment, while also positively affecting comorbid conditions arising as the disease progresses. For example, for those MS patients who also experience strokes, targeting the VIP/PACAP system could stimulate neuroprotection and neurogenesis, inhibit apoptosis and promote axon regeneration, while also triggering an antiinflammatory phenotype of activated glial cells, which could help preventing oligodendrocyte cell death [10, 216, 217].

PACAP and VIP have been tested in clinical trials as therapeutics for peripheral disorders such as arthritis [218], in which when injected intraperitoneally, the peptides reduced the incidence and severity of the disease, even when administered in the late stages [40]. Moreover, since data from the aforementioned migraine studies show that stimulating the VIP/PACAP system can lead to an increased incidence of migraines, several clinical trials are currently exploring the option of blocking VIP/PACAP activity in the brain to help migraine patients. Outside of the brain, there has been some success in using a VPAC2 agonist in asthma patients because of its bronchodilatory effects [219]. Of note, a recent study described the prospect of two well-known broad-spectrum antibiotics as potential compounds to target the PAC1 receptor. Doxycycline and Minocycline were shown to act as positive allosteric modulators of PAC1, stimulating axonal regeneration activities in cultured Schwann cells [191, 220]. These findings highlight that targeting the VIP/PACAP system is a feasible therapeutic approach for treating a spectrum of pathological conditions.

To achieve potential beneficial effects of PACAP and VIP in the CNS, passage through the blood brain barrier (BBB) must be improved. To overcome this issue, recently $\mathrm{Yu}$ and colleagues generated a VIP-TAT construct with enhanced efficiency to cross the BBB, which showed increased neuroprotection compared with VIP alone in an 1-methyl-4-phenyl1,2,3,6-tetrahydropyridine (MPTP) mouse model of Parkinson's disease $[221,222]$. Therefore, in view of the current advances in biotechnology, it is reasonable to anticipate more research into PACAP and VIP and more opportunities for 

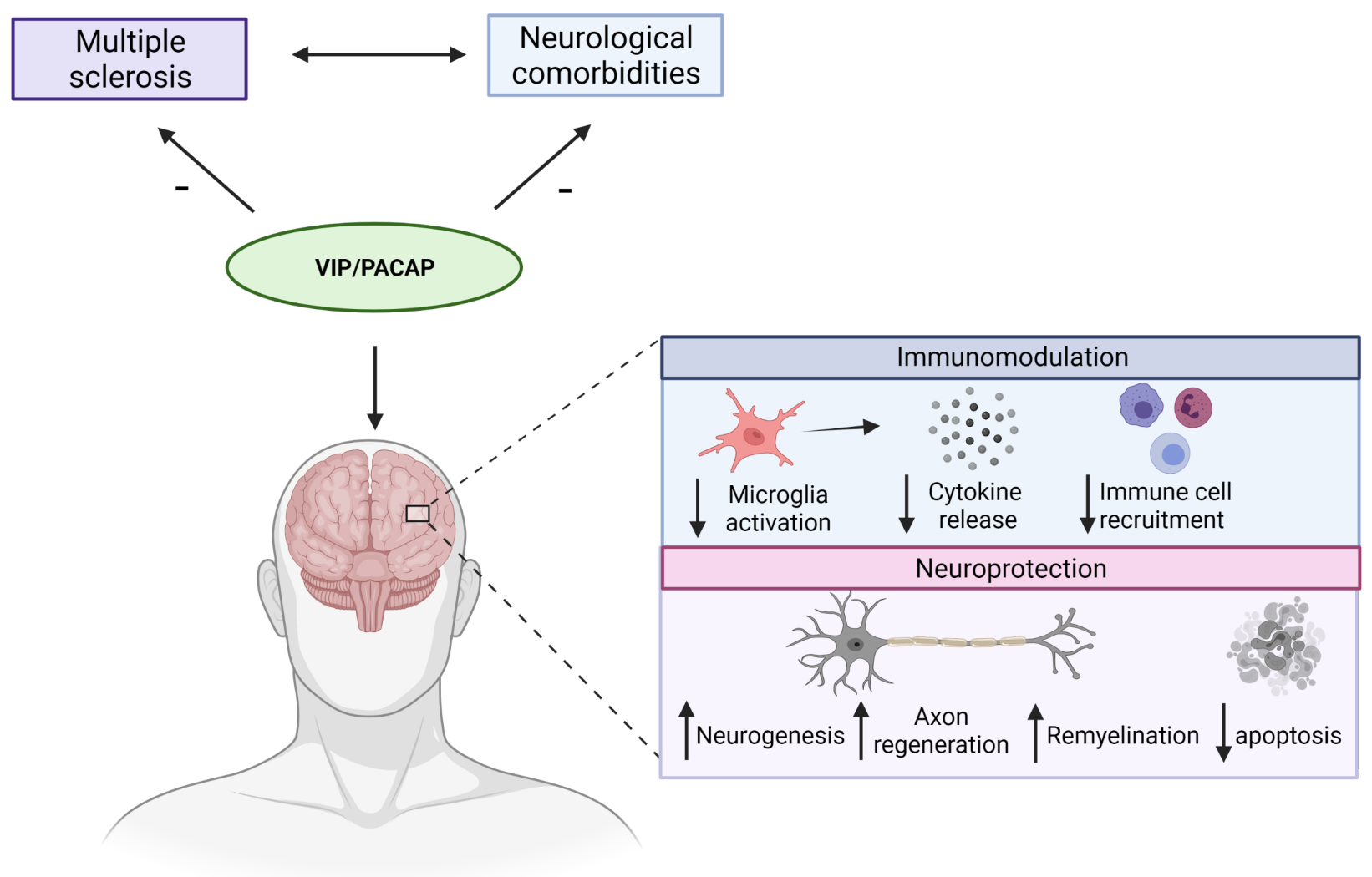

Fig. 2. Immunomodulation and neuroprotection functions of PACAP and VIP in multiple sclerosis and neurological comorbidities. Both PACAP and VIP are promising neuropeptides that can aid in MS and the associated neurological comorbidities of MS through the potent immunomodulatory actions and neuroprotective effects of both these peptides.

these peptides to be used as therapeutics for neurological and cognitive diseases.

However, it is important to recognize that targeting the VIP/PACAP system can come with its downsides. Since PACAP and VIP are pleiotropic molecules and can target different cell types within the CNS and periphery, it would require specialised administration strategies to deliver the peptides so that they can target the desired cell population or CNS region. Adeno-associated viruses and/or other vectors to deliver personalised gene therapy approaches are becoming closer to achieving the targeted administration of therapeutics to the brain via systemic route [223]. This could limit potential off-target effects by limiting the availability of peptides to, for example, the PAC1 receptor in cardiac cells [223].

Altogether, despite some yet to control side effects, the plethora of positive effects of both VIP and PACAP in the CNS justify the ongoing efforts to target this neuropeptide system using synthetic analogues or other technologies, with the aim to identify drug candidates with tropism towards selected CNS regions/tissues. This could result in an effective disease-modifying therapy able to improve MS disease course and prevent the development of most of the associated comorbidities.

\section{Conclusion \& future directions}

The VIP/PACAP system appears to have protective benefits in MS and most of its associated neurological comorbidities, making it an attractive therapeutic target to pursue (Fig. 2). With the recent advancements in CNS-targeted drug administration, there is more flexibility in treatment options as new ways of overcoming the challenge of delivering drugs that pass through the BBB or that impede rapid degradation are being developed. As such, future research can now explore the potential of PACAP and/or VIP as targets for the treatment of a range of neurological diseases that involve inflammation and consequently, neurodegeneration.

\section{Abbreviations}

ACTH, adrenocorticotrophic hormone; BBB, blood brain barrier; BD, bipolar disorder; BNST, bed nucleus of the stria terminalis; CNS, central nervous system; PNS, peripheral nervous system; CGRP, calcitonin gene-related peptide; DISC1, disrupted-in-schizophrenia 1; EAE, experimental autoimmune encephalomyelitis; GPCR, G protein-coupled receptors; HPA, hypothalamic-pituitaryadrenal; IL, interleukin; MPTP, 1-methyl-4-phenyl-1,2,3,6tetrahydropyridine; MRI, magnetic resonance imaging; MS, multiple sclerosis; NK, natural killer cells; NPY, neu- 
ropeptide Y; NSC, neural stem cells; NRG1, neuregulin-1; PACAP, pituitary adenylate cyclase-activating polypeptide; PNS, peripheral nervous system; SNPs, single nucleotide polymorphisms; RA, rheumatoid arthritis; VIP, vasoactive intestinal peptide; iNOS, inducible nitric oxide synthase; NO, nitric oxide.

\section{Author contributions}

MIJ and STB wrote the paper; AC conceived the study and revised the manuscript.

\section{Ethics approval and consent to participate Not applicable.}

\section{Acknowledgment}

We would like to thank all the members of the Laboratory of Cellular and Molecular Neuroscience for their critical insights on the paper.

\section{Funding}

This study was supported by grants from the Rebecca L. Cooper Medical Research Foundation (PG2020710 to AC).

\section{Conflict of interest}

The authors declare no conflict of interest.

\section{References}

[1] Borbély E, Scheich B, Helyes Z. Neuropeptides in learning and memory. Neuropeptides. 2013; 47: 439-450.

[2] Hökfelt T, Bartfai T, Bloom F. Neuropeptides: opportunities for drug discovery. Lancet Neurology. 2003; 2: 463-472.

[3] Souza-Moreira L, Campos-Salinas J, Caro M, Gonzalez-Rey E. Neuropeptides as Pleiotropic Modulators of the Immune Response. Neuroendocrinology. 2011; 94: 89-100.

[4] Hökfelt T, Broberger C, Xu ZQ, Sergeyev V, Ubink R, Diez M. Neuropeptides-an overview. Neuropharmacology. 2000; 39: 1337-1356.

[5] Catalani E, De Palma C, Perrotta C, Cervia D. Current Evidence for a Role of Neuropeptides in the Regulation of Autophagy. BioMed Research International. 2017; 2017: 1-10.

[6] Ben-Shushan S, Miller Y. Neuropeptides: Roles and Activities as Metal Chelators in Neurodegenerative Diseases. Journal of Physical Chemistry B. 2021; 125: 2796-2811.

[7] Chen X, Du Y, Chen L. Neuropeptides Exert Neuroprotective Effects in Alzheimer's Disease. Frontiers in Molecular Neuroscience. 2018; 11: 493.

[8] Werner F, Coveñas R. Classical Neurotransmitters and Neuropeptides involved in Parkinson's Disease: A Multi-Neurotransmitter System. Journal of Cytology \& Histology. 2014; 5: 5.

[9] Zheng Y, Zhang L, Xie J, Shi L. The Emerging Role of Neuropeptides in Parkinson's Disease. Frontiers in Aging Neuroscience. 2021; 13: 646726

[10] Waschek JA. VIP and PACAP: neuropeptide modulators of CNS inflammation, injury, and repair. British Journal of Pharmacology. 2013; 169: 512-523.

[11] Kohek SRB, Foresti ML, Blanco MM, Cavarsan CF, Da Silva CS, Mello LE. Anxious Profile Influences Behavioral and Immunohistological Findings in the Pilocarpine Model of Epilepsy. frontiers in pharmacology. 2021; 12: 640715.

[12] Troubat RAO, Barone P, Leman SAO, Desmidt TAO, Cressant A, Atanasova BAO, et al. Neuroinflammation and depression: A review. European journal of neuroscience. 2021; 53: 151-171.
[13] Lambertsen KL, Finsen B, Clausen BH. Post-stroke inflammation-target or tool for therapy? Acta Neuropathologica. 2019; 137: 693-714.

[14] Zhang Q, Han X, Wu H, Zhang M, Hu G, Dong Z, et al. Dynamic changes in CGRP, PACAP, and PACAP receptors in the trigeminovascular system of a novel repetitive electrical stimulation rat model: Relevant to migraine. Molecular Pain. 2019; 15: 1744806918820452.

[15] Dobolyi A, Kekesi KA, Juhasz G, Szekely AD, Lovas G, Kovacs Z. Receptors of Peptides as Therapeutic Targets in Epilepsy Research. Current Medicinal Chemistry. 2014; 21: 764-787.

[16] Carniglia L, Ramírez D, Durand D, Saba J, Turati J, Caruso C, et al. Neuropeptides and Microglial Activation in Inflammation, Pain, and Neurodegenerative Diseases. Mediators of Inflammation. 2017; 2017: 5048616.

[17] Tan Y, Waschek JA. Targeting VIP and PACAP receptor signalling: new therapeutic strategies in multiple sclerosis. ASN Neuro. 2011; 3: e00065.

[18] Duarte-Neves J, Pereira de Almeida L, Cavadas C. Neuropeptide $\mathrm{Y}(\mathrm{NPY})$ as a therapeutic target for neurodegenerative diseases. Neurobiology of Disease. 2016; 95: 210-224.

[19] Li C, Wu X, Liu S, Zhao Y, Zhu J, Liu K. Roles of Neuropeptide $\mathrm{Y}$ in Neurodegenerative and Neuroimmune Diseases. Frontiers in Neuroscience. 2019; 13: 869.

[20] Singh Y, Gupta G, Shrivastava B, Dahiya R, Tiwari J, Ashwathanarayana $\mathrm{M}$, et al. Calcitonin gene-related peptide (CGRP): a novel target for Alzheimer's disease. CNS Neuroscience \& Therapeutics. 2017; 23: 457-461.

[21] Song Y, Yoon J, Lee S. The role of neuropeptide somatostatin in the brain and its application in treating neurological disorders. Experimental \& Molecular Medicine. 2021; 53: 328-338.

[22] Castorina A, Vogiatzis M, Kang JWM, Keay KA. PACAP and VIP expression in the periaqueductal grey of the rat following sciatic nerve constriction injury. Neuropeptides. 2019; 74: 60-69.

[23] Tamas A, Reglodi D, Farkas O, Kovesdi E, Pal J, Povlishock JT, et al. Effect of PACAP in central and peripheral nerve injuries. International Journal of Molecular Sciences. 2012; 13: 8430-8448.

[24] Yang R, Jiang X, Ji R, Meng L, Liu F, Chen X, et al. Therapeutic potential of PACAP for neurodegenerative diseases. Cellular \& Molecular Biology Letters. 2015; 20: 265-278.

[25] Toth D, Tamas A, Reglodi D. The Neuroprotective and Biomarker Potential of PACAP in Human Traumatic Brain Injury. International journal of molecular sciences. 2020; 21: 827.

[26] Reglodi D, Vaczy A, Rubio-Beltran E, MaassenVanDenBrink A. Protective effects of PACAP in ischemia. Journal of Headache and Pain. 2018; 19: 19.

[27] Vaczy A, Kovari P, Kovacs K, Farkas K, Szabo E, Kvarik T, et al. Protective Role of Endogenous PACAP in Inflammation-induced Retinal Degeneration. Current Pharmaceutical Design. 2018; 24: 3534-3542.

[28] Hirabayashi T, Nakamachi T, Shioda S. Discovery of PACAP and its receptors in the brain. Journal of Headache and Pain. 2018; 19: 28.

[29] Reglodi D, Kiss P, Lubics A, Tamas A. Review on the protective effects of PACAP in models of neurodegenerative diseases in vitro and in vivo. Current Pharmaceutical Design. 2011; 17: 962-972.

[30] Dejda A, Jolivel V, Bourgault S, Seaborn T, Fournier A, Vaudry $\mathrm{H}$, et al. Inhibitory effect of PACAP on caspase activity in neuronal apoptosis: a better understanding towards therapeutic applications in neurodegenerative diseases. Journal of Molecular Neuroscience. 2008; 36: 26-37.

[31] Seaborn T, Masmoudi-Kouli O, Fournier A, Vaudry H, Vaudry D. Protective Effects of Pituitary Adenylate Cyclase-Activating Polypeptide (PACAP) against Apoptosis. Current Pharmaceutical Design. 2011; 17: 204-214.

[32] Ohtaki H, Nakamachi T, Dohi K, Aizawa Y, Takaki A, Hodoyama K, et al. Pituitary adenylate cyclase-activating polypeptide (PACAP) decreases ischemic neuronal cell death in association 
with IL-6. Proceedings of the National Academy of Sciences. 2006; 103: 7488-7493.

[33] Tsuchida M, Nakamachi T, Sugiyama K, Tsuchikawa D, Watanabe J, Hori M, et al. PACAP Stimulates Functional Recovery after Spinal Cord Injury through Axonal Regeneration. Journal of Molecular Neuroscience. 2014; 54: 380-387.

[34] Castorina A, Tiralongo A, Giunta S, Carnazza ML, Rasi G, D'Agata V. PACAP and VIP prevent apoptosis in schwannoma cells. Brain Research. 2008; 1241: 29-35.

[35] Stetler RA, Gao Y, Zukin RS, Vosler PS, Zhang L, Zhang $\mathrm{F}$, et al. Apurinic/apyrimidinic endonuclease APE1 is required for PACAP-induced neuroprotection against global cerebral ischemia. Proceedings of the National Academy of Sciences. 2010; 107: 3204-3209.

[36] Delgado M, Garrido E, Martinez C, Leceta J, Gomariz RP. Vasoactive intestinal peptide and pituitary adenylate cyclase-activating polypeptides (PACAP27) and PACAP38) protect CD4+ CD8+ thymocytes from glucocorticoid-induced apoptosis. Blood. 1996; 87: $5152-5161$.

[37] Abad C, Waschek JA. Immunomodulatory roles of VIP and PACAP in models of multiple sclerosis. Current Pharmaceutical Design. 2011; 17: 1025-1035.

[38] Gonzalez-Rey E, Delgado-Maroto V, Souza-Moreira L, Delgado M. Neuropeptides as Therapeutic Approach to Autoimmune Diseases. Current Pharmaceutical Design. 2010; 16: 3158-3172.

[39] Gonzalez-Rey E, Fernandez-Martin A, Chorny A, Martin J, Pozo $\mathrm{D}$, Ganea D, et al. Therapeutic Effect of Vasoactive Intestinal Peptide on Experimental Autoimmune Encephalomyelitis. American Journal of Pathology. 2006; 168: 1179-1188.

[40] Villanueva-Romero R, Gutiérrez-Cañas I, Carrión M, PérezGarcía S, Seoane IV, Martínez C, et al. The Anti-Inflammatory Mediator, Vasoactive Intestinal Peptide, Modulates the Differentiation and Function of Th Subsets in Rheumatoid Arthritis. Journal of Immunology Research. 2018; 2018: 1-11.

[41] Delgado M, Ganea D. Neuroprotective effect of vasoactive intestinal peptide (VIP) in a mouse model of Parkinson's disease by blocking microglial activation. American Societies for Experimental Biology. 2003; 17: 944-946.

[42] Parnell GP, Booth DR. The Multiple Sclerosis (MS) Genetic Risk Factors Indicate both Acquired and Innate Immune Cell Subsets Contribute to MS Pathogenesis and Identify Novel Therapeutic Opportunities. Frontiers in Immunology. 2017; 8: 425.

[43] Handel AE, Giovannoni G, Ebers GC, Ramagopalan SV. Environmental factors and their timing in adult-onset multiple sclerosis. Nature Reviews. Neurology. 2010; 6: 156-166.

[44] Walton C, King R, Rechtman L, Kaye W, Leray E, Marrie RA, et al. Rising prevalence of multiple sclerosis worldwide: Insights from the Atlas of MS, third edition. Multiple Sclerosis Journal. 2020; 26: 1816-1821.

[45] Yamout BI, Alroughani R. Multiple Sclerosis. Seminars in Neurology. 2018; 38: 212-225.

[46] Høglund RA, Maghazachi AA. Multiple sclerosis and the role of immune cells. World Journal of Experimental Medicine. 2014; 4: 27-37.

[47] Hemmer B, Kerschensteiner M, Korn T. Role of the innate and adaptive immune responses in the course of multiple sclerosis. Lancet Neurology. 2015; 14: 406-419.

[48] Lopes Pinheiro MA, Kooij G, Mizee MR, Kamermans A, Enzmann G, Lyck R, et al. Immune cell trafficking across the barriers of the central nervous system in multiple sclerosis and stroke. Biochimica et Biophysica Acta. 2016; 1862: 461-471.

[49] Simkins TJ, Duncan GJ, Bourdette D. Chronic Demyelination and Axonal Degeneration in Multiple Sclerosis: Pathogenesis and Therapeutic Implications. Current Neurology and Neuroscience Reports. 2021; 21: 26.

[50] Baranowska-Bik A, Kochanowski J, Uchman D, WolinskaWitort E, Kalisz M, Martynska L, et al. Vasoactive intestinal peptide (VIP) and pituitary adenylate cyclase activating polypeptide (PACAP) in humans with multiple sclerosis. Journal of Neuroim- munology. 2013; 263: 159-161.

[51] Tan Y, Abad C, Lopez R, Dong H, Liu S, Lee A, et al. Pituitary adenylyl cyclase-activating polypeptide is an intrinsic regulator of Treg abundance and protects against experimental autoimmune encephalomyelitis. Proceedings of the National Academy of Sciences. 2009; 106: 2012-2017.

[52] Tan Y, Abad C, Wang Y, Lopez R, Waschek JA. Pituitary adenylate cyclase activating peptide deficient mice exhibit impaired thymic and extrathymic regulatory $\mathrm{T}$ cell proliferation during EAE. PLoS ONE. 2013; 8: e61200.

[53] Abad C, Jayaram B, Becquet L, Wang Y, O'Dorisio MS, Waschek JA, et al. VPAC1 receptor (Vipr1)-deficient mice exhibit ameliorated experimental autoimmune encephalomyelitis, with specific deficits in the effector stage. Journal of Neuroinflammation. 2016; 13: 169.

[54] Atlasz T, Szabadfi K, Kiss P, Racz B, Gallyas F, Tamas A, et al. Pituitary adenylate cyclase activating polypeptide in the retina: focus on the retinoprotective effects. Annals of the New York Academy of Sciences. 2010; 1200: 128-139.

[55] Tan Y, Abad C, Wang Y, Lopez R, Waschek JA. VPAC2 (vasoactive intestinal peptide receptor type 2 ) receptor deficient mice develop exacerbated experimental autoimmune encephalomyelitis with increased Th1/Th17 and reduced Th2/Treg responses. Brain, Behavior, and Immunity. 2015; 44: 167-175.

[56] Kato H, Ito A, Kawanokuchi J, Jin S, Mizuno T, Ojika K, et al. Pituitary adenylate cyclase-activating polypeptide (PACAP) ameliorates experimental autoimmune encephalomyelitis by suppressing the functions of antigen presenting cells. Multiple Sclerosis. 2004; 10: 651-659.

[57] Delgado M, Gonzalez-Rey E, Ganea D. VIP/PACAP preferentially attract Th2 effectors through differential regulation of chemokine production by dendritic cells. Federation of American Societies for Experimental Biology. 2004; 18: 1453-1455.

[58] Delgado M, Jonakait GM, Ganea D. Vasoactive intestinal peptide and pituitary adenylate cyclase-activating polypeptide inhibit chemokine production in activated microglia. Glia. 2002; 39: 148 161.

[59] Delgado M, Leceta J, Ganea D. Vasoactive intestinal peptide and pituitary adenylate cyclase-activating polypeptide inhibit the production of inflammatory mediators by activated microglia. Journal of Leukocyte Biology. 2003; 73: 155-164.

[60] Murphy R, O’Donoghue S, Counihan T, McDonald C, Calabresi PA, Ahmed MA, et al. Neuropsychiatric syndromes of multiple sclerosis. Journal of Neurology, Neurosurgery, and Psychiatry. 2017; 88: 697-708.

[61] Martinez C, Delgado M, Pozo D, Leceta J, Calvo JR, Ganea D, et al. VIP and PACAP enhance IL-6 release and mRNA levels in resting peritoneal macrophages: in vitro and in vivo studies. Journal of Neuroimmunology. 1998; 85: 155-167.

[62] Ganea D, Delgado M. Neuropeptides as modulators of macrophage functions. Regulation of cytokine production and antigen presentation by VIP and PACAP. Archivum immunologiae et therapiae experimentalis. 2001; 49: 101-110.

[63] Delgado M, Pozo D, Martinez C, Leceta J, Calvo JR, Ganea D, et al. Vasoactive Intestinal Peptide and Pituitary Adenylate CyclaseActivating Polypeptide Inhibit Endotoxin-Induced TNF- $\alpha$ Production by Macrophages: In Vitro and In Vivo Studies. The Journal of Immunology. 1999; 162: 2358-2367.

[64] Brown D, Tamas A, Reglodi D, Tizabi Y. PACAP protects against inflammatory-mediated toxicity in dopaminergic SH-SY5Y cells: implication for Parkinson's disease. Neurotoxicity Research. 2014; 26: 230-239.

[65] Gutcher I, Becher B. APC-derived cytokines and T cell polarization in autoimmune inflammation. Journal of Clinical Investigation. 2007; 117: 1119-1127.

[66] Leggio GM, Camillieri G, Platania CBM, Castorina A, Marrazzo $\mathrm{G}$, Torrisi SA, et al. Dopamine D3 receptor is necessary for ethanol consumption: an approach with buspirone. Neuropsychopharmacology. 2014; 39: 2017-2028. 
[67] Maduna T, Lelievre V. Neuropeptides shaping the central nervous system development: Spatiotemporal actions of VIP and PACAP through complementary signaling pathways. Journal of Neuroscience Research. 2016; 94: 1472-1487.

[68] Lelievre V, Ghiani CA, Seksenyan A, Gressens P, De Vellis J, Waschek JA. Growth factor-dependent actions of PACAP on oligodendrocyte progenitor proliferation. Regulatory Peptides. 2006; 137: 58-66.

[69] Lee M, Lelievre V, Zhao P, Torres M, Rodriguez W, Byun JY, et al. Pituitary adenylyl cyclase-activating polypeptide stimulates DNA synthesis but delays maturation of oligodendrocyte progenitors. Journal of Neuroscience. 2001; 21: 3849-3859.

[70] Vincze A, Reglodi D, Helyes Z, Hashimoto H, Shintani N, Abrahám H. Role of endogenous pituitary adenylate cyclase activating polypeptide (PACAP) in myelination of the rodent brain: lessons from PACAP-deficient mice. International Journal of Developmental Neuroscience. 2011; 29: 923-935.

[71] Yan Y, Zhou X, Pan Z, Ma J, Waschek JA, DiCicco-Bloom E. Pro- and anti-mitogenic actions of pituitary adenylate cyclaseactivating polypeptide in developing cerebral cortex: potential mediation by developmental switch of PAC1 receptor mRNA isoforms. Journal of Neuroscience. 2013; 33: 3865-3878.

[72] Armstrong BD, Abad C, Chhith S, Cheung-Lau G, Hajji OE, Nobuta $\mathrm{H}$, et al. Impaired nerve regeneration and enhanced neuroinflammatory response in mice lacking pituitary adenylyl cyclase activating peptide. Neuroscience. 2008; 151: 63-73.

[73] Maugeri G, D’Amico AG, Musumeci G, Reglodi D, D'Agata V. Effects of Pacap on Schwann Cells: Focus on Nerve Injury. International Journal of Molecular Sciences. 2020; 21: 8233.

[74] Woodley PK, Min Q, Li Y, Mulvey NF, Parkinson DB, Dun XP. Distinct VIP and PACAP Functions in the Distal Nerve Stump During Peripheral Nerve Regeneration. Frontiers in Neuroscience. 2019; 13: 1326.

[75] Castorina A, Scuderi S, D'Amico AG, Drago F, D'Agata V. PACAP and VIP increase the expression of myelin-related proteins in rat schwannoma cells: involvement of PAC1/VPAC2 receptormediated activation of PI3K/Akt signaling pathways. Experimental Cell Research. 2014; 322: 108-121.

[76] Favrais G, Couvineau A, Laburthe M, Gressens P, Lelievre V. Involvement of VIP and PACAP in neonatal brain lesions generated by a combined excitotoxic/inflammatory challenge. Peptides. 2007; 28: 1727-1737.

[77] Zhang Q, Liu J, Lin P, Webster HD. Local administration of vasoactive intestinal peptide after nerve transection accelerates early myelination and growth of regenerating axons. Journal of the Peripheral Nervous System. 2002; 7: 118-127.

[78] Magyari M, Sorensen PS. Comorbidity in Multiple Sclerosis. Frontiers in Neuroscience. 2020; 11: 851.

[79] Marrie RA, Cohen J, Stuve O, Trojano M, Sørensen PS, Reingold $\mathrm{S}$, et al. A systematic review of the incidence and prevalence of comorbidity in multiple sclerosis: overview. Multiple Sclerosis. 2015; 21: 263-281.

[80] Thormann A, Magyari M, Koch-Henriksen N, Laursen B, Sørensen PS. Vascular comorbidities in multiple sclerosis: a nationwide study from Denmark. Journal of Neurology. 2016; 263: 2484-2493.

[81] Tettey P, Simpson S, Taylor BV, van der Mei IAF. The cooccurrence of multiple sclerosis and type 1 diabetes: shared aetiologic features and clinical implication for MS aetiology. Journal of the Neurological Sciences. 2015; 348: 126-131.

[82] Panda SP, Das RC, Srivastava K, Ratnam A, Sharma N. Psychiatric comorbidity in multiple sclerosis. Neurologia i Neurochirurgia Polska. 2018; 52: 704-709.

[83] Schorner A, Weissert R. Patients with Epileptic Seizures and Multiple Sclerosis in a Multiple Sclerosis Center in Southern Germany between 2003-2015. Frontiers in Neurology. 2019; 10: 613.

[84] Pakpoor J, Handel AE, Giovannoni G, Dobson R, Ramagopalan SV. Meta-analysis of the relationship between multiple sclerosis and migraine. PLoS ONE. 2012; 7: e45295.
[85] Benedetti F, Aggio V, Pratesi ML, Greco G, Furlan R. Neuroinflammation in Bipolar Depression. Frontiers in Psychiatry. 2020; 11: 71.

[86] Cernackova A, Durackova Z, Trebaticka J, Mravec B. Neuroinflammation and depressive disorder: the role of the hypothalamus. Journal of Clinical Neuroscience. 2020; 75: 5-10.

[87] Sani G, Panaccione I, Spalletta G. Neuroinflammation and excitatory symptoms in bipolar disorder. Neuroimmunology and Neuroinflammation. 2015; 2: 215.

[88] Won E, Kim YK. Neuroinflammation-Associated Alterations of the Brain as Potential Neural Biomarkers in Anxiety Disorders. International Journal of Molecular Sciences. 2020; 21: 6546.

[89] Cathomas F, Azzinnari D, Bergamini G, Sigrist H, Buerge M, Hoop V, et al. Oligodendrocyte gene expression is reduced by and influences effects of chronic social stress in mice. Genes, Brain, and Behavior. 2019; 18: e12475.

[90] Miyata S, Taniguchi M, Koyama Y, Shimizu S, Tanaka T, Yasuno $\mathrm{F}$, et al. Association between chronic stress-induced structural abnormalities in Ranvier nodes and reduced oligodendrocyte activity in major depression. Scientific Reports. 2016; 6: 23084.

[91] Tohyama M, Miyata S, Hattori T, Shimizu S, Matsuzaki S. Molecular basis of major psychiatric diseases such as schizophrenia and depression. Anatomical Science International. 2015; 90: 137-143.

[92] Daban C, Vieta E, Mackin P, Young AH. Hypothalamic-pituitaryadrenal axis and bipolar disorder. Psychiatric Clinics of North America. 2005; 28: 469-480.

[93] Saccaro LF, Schilliger Z, Dayer A, Perroud N, Piguet C. Inflammation, anxiety, and stress in bipolar disorder and borderline personality disorder: a narrative review. Neuroscience \& Biobehavioral Reviews. 2021; 127: 184-192.

[94] Robinson SL, Thiele TE. A role for the neuropeptide somatostatin in the neurobiology of behaviors associated with substances abuse and affective disorders. Neuropharmacology. 2020; 167: 107983.

[95] Khairuddin S, Aquili L, Heng BC, Hoo TLC, Wong KH, Lim LW. Dysregulation of the orexinergic system: a potential neuropeptide target in depression. Neuroscience \& Biobehavioral Reviews. 2020; 118: 384-396.

[96] Kormos V, Gaszner B. Role of neuropeptides in anxiety, stress, and depression: from animals to humans. Neuropeptides. 2013; 47: 401-419.

[97] Mathé AA, Michaneck M, Berg E, Charney DS, Murrough JW. A Randomized Controlled Trial of Intranasal Neuropeptide Y in Patients with Major Depressive Disorder. International Journal of Neuropsychopharmacology. 2020; 23: 783-790.

[98] Treutlein J, Strohmaier J, Frank J, Witt SH, Rietschel L, Forstner $\mathrm{AJ}$, et al. Association between neuropeptide $\mathrm{Y}$ receptor Y2 promoter variant rs6857715 and major depressive disorder. Psychiatric Genetics. 2017; 27: 34-37.

[99] Wang Y, Yang Y, Hui L, Tie C, Li F, Xu ZD, et al. A neuropeptide $Y$ variant (rs16139) associated with major depressive disorder in replicate samples from Chinese Han population. PLoS ONE. 2013; 8: e57042.

[100] Demsie DG, Altaye BM, Weldekidan E, Gebremedhin H, Alema NM, Tefera MM, et al. Galanin Receptors as Drug Target for Novel Antidepressants: Review. Biologics. 2020; 14: 37-45.

[101] Keszler G, Molnar Z, Ronai Z, Sasvari-Szekely M, Szekely A, Kotyuk E. Association between anxiety and non-coding genetic variants of the galanin neuropeptide. PLoS ONE. 2019; 14: e0226228.

[102] Farkas J, Kovács LÁ, Gáspár L, Nafz A, Gaszner T, Ujvári B, et al. Construct and face validity of a new model for the three-hit theory of depression using PACAP mutant mice on CD1 background. Neuroscience. 2017; 354: 11-29.

[103] Gaszner B, Kormos V, Kozicz T, Hashimoto H, Reglodi D, Helyes Z. The behavioral phenotype of pituitary adenylate-cyclase activating polypeptide-deficient mice in anxiety and depression tests is accompanied by blunted c-Fos expression in the bed nucleus of the stria terminalis, central projecting Edinger-Westphal nucleus, ventral lateral septum, and dorsal raphe nucleus. Neuroscience. 2012; 202: 283-299. 
[104] Kormos V, Gáspár L, Kovács L, Farkas J, Gaszner T, Csernus V, et al. Reduced response to chronic mild stress in PACAP mutant mice is associated with blunted FosB expression in limbic forebrain and brainstem centers. Neuroscience. 2016; 330: 335-358.

[105] Lehmann ML, Mustafa T, Eiden AM, Herkenham M, Eiden LE. PACAP-deficient mice show attenuated corticosterone secretion and fail to develop depressive behavior during chronic social defeat stress. Psychoneuroendocrinology. 2013; 38: 702-715.

[106] Simon RA, Barazanji N, Jones MP, Bednarska O, Icenhour A, Engström $\mathrm{M}$, et al. Vasoactive intestinal polypeptide plasma levels associated with affective symptoms and brain structure and function in healthy females. Scientific Reports. 2021; 11: 1406.

[107] Huang Y, Yu J, Wang G, Chen Z, Wang Q, Xiao L. Effect of fluoxetine on depression-induced changes in the expression of vasoactive intestinal polypeptide and corticotrophin releasing factor in rat duodenum. World Journal of Gastroenterology. 2007; 13: 6060-6065.

[108] Soria V, Martínez-Amorós E, Escaramís G, Valero J, Pérez-Egea R, García C, et al. Differential Association of Circadian Genes with Mood Disorders: CRY1 and NPAS2 are Associated with Unipolar Major Depression and CLOCK and VIP with Bipolar Disorder. Neuropsychopharmacology. 2010; 35: 1279-1289.

[109] Ivanova M, Belcheva S, Belcheva I, Stoyanov Z, Tashev R. Modulatory effect of VIP injected into hippocampal CA1 area on anxiety in olfactory bulbectomized rats. Acta neurobiologiae experimentalis. 2014; 74: 317-327.

[110] Almeida FB, Pinna G, Barros HMT. The Role of HPA Axis and Allopregnanolone on the Neurobiology of Major Depressive Disorders and PTSD. International Journal of Molecular Sciences. 2021; 22: 5495.

[111] Tafet GE, Nemeroff CB. Pharmacological Treatment of Anxiety Disorders: The Role of the HPA Axis. Frontiers in Psychiatry. 2020; 11: 443.

[112] Jiang SZ, Eiden LE. Activation of the HPA axis and depression of feeding behavior induced by restraint stress are separately regulated by PACAPergic neurotransmission in the mouse. Stress. 2016; 19: 374-382.

[113] Iemolo A, Seiglie M, Blasio A, Cottone P, Sabino V. Pituitary adenylate cyclase-activating polypeptide (PACAP) in the central nucleus of the amygdala induces anxiety via melanocortin receptors. Psychopharmacology. 2016; 233: 3269-3277.

[114] Missig G, Roman CW, Vizzard MA, Braas KM, Hammack SE, May V. Parabrachial nucleus (PBn) pituitary adenylate cyclase activating polypeptide (PACAP) signaling in the amygdala: implication for the sensory and behavioral effects of pain. Neuropharmacology. 2014; 86: 38-48.

[115] Lezak KR, Roelke E, Harris OM, Choi I, Edwards S, Gick N, et al. Pituitary adenylate cyclase-activating polypeptide (PACAP) in the bed nucleus of the stria terminalis (BNST) increases corticosterone in male and female rats. Psychoneuroendocrinology. 2014; 45: 1120.

[116] Hammack SE, Cheung J, Rhodes KM, Schutz KC, Falls WA, Braas KM, et al. Chronic stress increases pituitary adenylate cyclase-activating peptide (PACAP) and brain-derived neurotrophic factor (BDNF) mRNA expression in the bed nucleus of the stria terminalis (BNST): Roles for PACAP in anxiety-like behavior. Psychoneuroendocrinology. 2009; 34: 833-843.

[117] Loh DH, Abad C, Colwell CS, Waschek JA. Vasoactive intestinal peptide is critical for circadian regulation of glucocorticoids. Neuroendocrinology. 2008; 88: 246-255.

[118] Patten SB, Svenson LW, Metz LM. Psychotic disorders in MS: population-based evidence of an association. Neurology. 2005; 65: $1123-1125$.

[119] Barron H, Hafizi S, Andreazza AC, Mizrahi R. Neuroinflammation and Oxidative Stress in Psychosis and Psychosis Risk. International Journal of Molecular Sciences. 2017; 18: 651.

[120] Najjar S, Pearlman DM, Alper K, Najjar A, Devinsky O. Neuroinflammation and psychiatric illness. Journal of Neuroinflammation. 2013; 10: 43.
[121] Rodríguez B, Nani JV, Almeida PGC, Brietzke E, Lee RS, Hayashi MAF. Neuropeptides and oligopeptidases in schizophrenia. Neuroscience \& Biobehavioral Reviews. 2020; 108: 679-693.

[122] Cáceda R, Kinkead B, Nemeroff CB. Involvement of neuropeptide systems in schizophrenia: human studies. International Review of Neurobiology. 2007; 78: 327-376.

[123] Zheng C, Fu Q, Shen Y, Xu Q. Investigation of allelic heterogeneity of the CCK-a receptor gene in paranoid schizophrenia. American Journal of Medical Genetics. 2012; 159B: 741-747.

[124] Tachikawa H, Harada S, Kawanishi Y, Okubo T, Suzuki T. Linked polymorphisms $(-333 \mathrm{G}>\mathrm{T}$ and $-286 \mathrm{a}>\mathrm{G})$ in the promoter region of the CCK-a receptor gene may be associated with schizophrenia. Psychiatry Research. 2001; 103: 147-155.

[125] Kukshal P, Bhatia T, Bhagwat AM, Gur RE, Gur RC, Deshpande $\mathrm{SN}$, et al. Association study of neuregulin-1 gene polymorphisms in a North Indian schizophrenia sample. Schizophrenia Research. 2013; 144: 24-30.

[126] Law AJ, Lipska BK, Weickert CS, Hyde TM, Straub RE, Hashimoto R, et al. Neuregulin 1 transcripts are differentially expressed in schizophrenia and regulated by 5 ' SNPs associated with the disease. Proceedings of the National Academy of Sciences of the United States of America. 2006; 103: 6747-6752.

[127] Prata DP, Breen G, Osborne S, Munro J, Clair DS, Collier DA. An association study of the neuregulin 1 gene, bipolar affective disorder and psychosis. Psychiatric Genetics. 2009; 19: 113-116.

[128] Levinson DF, Duan J, Oh S, Wang K, Sanders AR, Shi J, et al. Copy number variants in schizophrenia: confirmation of five previous findings and new evidence for 3q29 microdeletions and VIPR2 duplications. American Journal of Psychiatry. 2011; 168: 302-316.

[129] Hashimoto R, Hashimoto H, Shintani N, Chiba S, Hattori S, Okada $\mathrm{T}$, et al. Pituitary adenylate cyclase-activating polypeptide is associated with schizophrenia. Molecular Psychiatry. 2007; 12: 1026-1032.

[130] Nieratschker V, Meyer-Lindenberg A, Witt SH. Genome-wide investigation of rare structural variants identifies VIPR2 as a new candidate gene for schizophrenia. Expert Review of Neurotherapeutics. 2011; 11: 937-941.

[131] Tian X, Richard A, El-Saadi MW, Bhandari A, Latimer B, Van Savage I, et al. Dosage sensitivity intolerance of VIPR2 microduplication is disease causative to manifest schizophrenia-like phenotypes in a novel BAC transgenic mouse model. Molecular Psychiatry. 2019; 24: 1884-1901.

[132] Jin C, Zhou Z, Li W, Zhang F, Yuan J, Liu X, et al. Analysis of the association of VIPR2 polymorphisms with susceptibility to schizophrenia. Psychiatry Research. 2017; 241: 104-107.

[133] Koga M, Ishiguro H, Horiuchi $Y$, Inada $T$, Ujike $H$, Itokawa $M$, et al. Replication study of association between ADCYAP1 gene polymorphisms and schizophrenia. Psychiatric Genetics. 2010; 20: 123-125.

[134] Boerrigter D, Weickert TW, Lenroot R, O’Donnell M, Galletly C, Liu D, et al. Using blood cytokine measures to define high inflammatory biotype of schizophrenia and schizoaffective disorder. Journal of Neuroinflammation. 2018; 14: 188.

[135] Rodrigues-Amorim D, Rivera-Baltanás T, Spuch C, Caruncho HJ, González-Fernandez Á, Olivares JM, et al. Cytokines dysregulation in schizophrenia: a systematic review of psychoneuroimmune relationship. Schizophrenia Research. 2019; 197: 19-33.

[136] van Berckel BN, Bossong MG, Boellaard R, Kloet R, Schuitemaker A, Caspers E, et al. Microglia activation in recent-onset schizophrenia: a quantitative (R)-[11C] PK11195 positron emission tomography study. Biological Psychiatry. 2008; 64: 820-822.

[137] Najjar S, Pearlman DM. Neuroinflammation and white matter pathology in schizophrenia: systematic review. Schizophrenia Research. 2015; 161: 102-112.

[138] Owen MJ, O’Donovan MC. Schizophrenia and the neurodevelopmental continuum: evidence from genomics. World Psychiatry. 2017; 16: 227-235. 
[139] Rund BR. The research evidence for schizophrenia as a neurodevelopmental disorder. Scandinavian Journal of Psychology. 2018; 59: 49-58.

[140] Reif A, Fritzen S, Finger M, Strobel A, Lauer M, Schmitt A, et al. Neural stem cell proliferation is decreased in schizophrenia, but not in depression. Molecular Psychiatry. 2006; 11: 514-522.

[141] Ruiz S, Birbaumer N, Sitaram R. Abnormal Neural Connectivity in Schizophrenia and fMRI-Brain-Computer Interface as a Potential Therapeutic Approach. Frontiers in Psychiatry. 2013; 4: 17.

[142] Du F, Cooper AJ, Thida T, Shinn AK, Cohen BM, Öngür D. Myelin and Axon Abnormalities in Schizophrenia Measured with Magnetic Resonance Imaging Techniques. Biological Psychiatry. 2013; 74: 451-457.

[143] Mukai J, Tamura M, Fénelon K, Rosen AM, Spellman TJ, Kang $\mathrm{R}$, et al. Molecular substrates of altered axonal growth and brain connectivity in a mouse model of schizophrenia. Neuron. 2015; 86: 680-695.

[144] Hattori T, Baba K, Matsuzaki S, Honda A, Miyoshi K, Inoue K, et al. A novel DISC1-interacting partner DISC1-Binding Zinc-finger protein: implication in the modulation of DISC1-dependent neurite outgrowth. Molecular Psychiatry. 2007; 12: 398-407.

[145] Taveggia C, Zanazzi G, Petrylak A, Yano H, Rosenbluth J, Einheber S, et al. Neuregulin-1 type III determines the ensheathment fate of axons. Neuron. 2005; 47: 681-694.

[146] Wood JD, Bonath F, Kumar S, Ross CA, Cunliffe VT. Disruptedin-schizophrenia 1 and neuregulin 1 are required for the specification of oligodendrocytes and neurones in the zebrafish brain. Human Molecular Genetics. 2009; 18: 391-404.

[147] Katayama T, Hattori T, Yamada K, Matsuzaki S, Tohyama M. Role of the PACAP-PAC1-DISC1 and PACAP-PAC1-stathmin1 systems in schizophrenia and bipolar disorder: novel treatment mechanisms? Pharmacogenomics. 2009; 10: 1967-1978.

[148] Ogata K, Shintani N, Hayata-Takano A, Kamo T, Higashi S, Seiriki $\mathrm{K}$, et al. PACAP enhances axon outgrowth in cultured hippocampal neurons to a comparable extent as BDNF. PLoS ONE. 2015; 10: e0120526.

[149] Mansouri S, Agartz I, Ögren S, Patrone C, Lundberg M. PACAP Protects Adult Neural Stem Cells from the Neurotoxic Effect of Ketamine Associated with Decreased Apoptosis, ER Stress and mTOR Pathway Activation. PLoS ONE. 2017; 12: e0170496.

[150] Mercer A, Rönnholm H, Holmberg J, Lundh H, Heidrich J, Zachrisson $\mathrm{O}$, et al. PACAP promotes neural stem cell proliferation in adult mouse brain. Journal of Neuroscience Research. 2004; 76: $205-215$.

[151] Jóźwiak-Bębenista M, Kowalczyk E. Neuroleptic Drugs and PACAP Differentially Affect the mRNA Expression of Genes Encoding PAC1/VPAC Type Receptors. Neurochemical Research. 2017; 42: 943-952.

[152] Clynen E, Swijsen A, Raijmakers M, Hoogland G, Rigo J. Neuropeptides as Targets for the Development of Anticonvulsant Drugs. Molecular Neurobiology. 2014; 50: 626-646.

[153] Kovac S, Walker MC. Neuropeptides in epilepsy. Neuropeptides. 2013; 47: 467-475.

[154] Poser CM, Brinar VV. Epilepsy and multiple sclerosis. Epilepsy \& Behavior. 2003; 4: 6-12.

[155] Bustuchina Vlaicu M. Epilepsy in multiple sclerosis as a network disease. Multiple Sclerosis and Related Disorders. 2019; 36: 101390.

[156] Nomura M, Ueta Y, Hannibal J, Serino R, Yamamoto Y, Shibuya I, et al. Induction of pituitary adenylate cyclase-activating polypeptide mRNA in the medial parvocellular part of the paraventricular nucleus of rats following kainic-acid-induced seizure. Neuroendocrinology. 2000; 71: 318-326.

[157] de Lanerolle NC, Gunel M, Sundaresan S, Shen MY, Brines ML, Spencer DD. Vasoactive intestinal polypeptide and its receptor changes in human temporal lobe epilepsy. Brain Research. 1995; 686: 182-193.

[158] Banerjee A, Sahu JK, Sankhyan N, Pattanaik S, Suthar R, Saini AG, et al. Randomized trial of high-dose pyridoxine in combina- tion with standard hormonal therapy in West syndrome. Seizure. 2021; 91: 75-80.

[159] Smith CB, Eiden LE. Is PACAP the major neurotransmitter for stress transduction at the adrenomedullary synapse? Journal of Molecular Neuroscience. 2012; 48: 403-412.

[160] Mazuski C, Abel JH, Chen SP, Hermanstyne TO, Jones JR, Simon $\mathrm{T}$, et al. Entrainment of Circadian Rhythms Depends on Firing Rates and Neuropeptide Release of VIP SCN Neurons. Neuron. 2018; 99: 555-563.e5.

[161] Cunha-Reis D, Caulino-Rocha A. VIP Modulation of Hippocampal Synaptic Plasticity: A Role for VIP Receptors as Therapeutic Targets in Cognitive Decline and Mesial Temporal Lobe Epilepsy. Frontiers in Cellular Neuroscience. 2020; 14: 153.

[162] Goff KM, Goldberg EM. A Role for Vasoactive Intestinal Peptide Interneurons in Neurodevelopmental Disorders. Developmental Neuroscience. 2021; 1: 1-13.

[163] Bhandare AM, Kapoor K, Farnham MMJ, Pilowsky PM. Microglia PACAP and glutamate: Friends or foes in seizure-induced autonomic dysfunction and SUDEP? Respiratory Physiology \& Neurobiology. 2016; 226: 39-50.

[164] Bhandare AM, Kapoor K, Powell KL, Braine E, Casillas-Espinosa $\mathrm{P}$, O'Brien TJ, et al. Inhibition of microglial activation with minocycline at the intrathecal level attenuates sympathoexcitatory and proarrhythmogenic changes in rats with chronic temporal lobe epilepsy. Neuroscience. 2017; 350: 23-38.

[165] Bhandare AM, Mohammed S, Pilowsky PM, Farnham MMJ. Antagonism of PACAP or Microglia Function Worsens the Cardiovascular Consequences of Kainic-Acid-Induced Seizures in Rats. Journal of Neuroscience. 2015; 35: 2191-2199.

[166] Shoge K, Mishima HK, Saitoh T, Ishihara K, Tamura Y, Shiomi $\mathrm{H}$, et al. Attenuation by PACAP of glutamate-induced neurotoxicity in cultured retinal neurons. Brain Research. 1999; 839: 66-73.

[167] Figiel M, Engele J. Pituitary adenylate cyclase-activating polypeptide (PACAP), a neuron-derived peptide regulating glial glutamate transport and metabolism. Journal of Neuroscience. 2000; 20: 3596-3605.

[168] Feigin VL, Nguyen G, Cercy K, Johnson CO, Alam T, Parmar PG, et al. Global, Regional, and Country-Specific Lifetime Risks of Stroke, 1990 and 2016. New England Journal of Medicine. 2018; 379: 2429-2437.

[169] Fang Y, Ren R, Shi H, Huang L, Lenahan C, Lu Q, et al. Pituitary Adenylate Cyclase-Activating Polypeptide: a Promising Neuroprotective Peptide in Stroke. Aging and Disease. 2020; 11: 1496.

[170] Hong Y, Tang HR, Ma M, Chen N, Xie X, He L. Multiple sclerosis and stroke: a systematic review and meta-analysis. BMC Neurology. 2019; 19: 139.

[171] Anrather J, Iadecola C. Inflammation and Stroke: an Overview. Neurotherapeutics. 2016; 13: 661-670.

[172] Jaworski DM. Expression of pituitary adenylate cyclaseactivating polypeptide (PACAP) and the PACAP-selective receptor in cultured rat astrocytes, human brain tumors, and in response to acute intracranial injury. Cell and Tissue Research. 2000; 300: 219-230.

[173] Masmoudi-Kouki O, Gandolfo P, Castel H, Leprince J, Fournier A, Dejda A, et al. Role of PACAP and VIP in astroglial functions. Peptides. 2007; 28: 1753-1760.

[174] Castorina A, Szychlinska M, Marzagalli R, Musumeci G. Mesenchymal stem cells-based therapy as a potential treatment in neurodegenerative disorders: is the escape from senescence an answer? Neural Regeneration Research. 2015; 10: 850.

[175] Yang J, Shi Q, Yang Y, Qian Y, Feng G, Chang L, et al. Vasoactive intestinal peptide administration after stroke in rats enhances neurogenesis and improves neurological function. Brain Research. 2015; 1625: 189-197.

[176] Nonaka N, Banks WA, Shioda S. Pituitary adenylate cyclaseactivating polypeptide: Protective effects in stroke and dementia. Peptides. 2020; 130: 170332.

[177] Moody TW, Ito T, Osefo N, Jensen RT. VIP and PACAP: recent insights into their functions/roles in physiology and disease from 
molecular and genetic studies. Current Opinion in Endocrinology, Diabetes, and Obesity. 2011; 18: 61-67.

[178] Cherait A, Maucotel J, Lefranc B, Leprince J, Vaudry D. Intranasal Administration of PACAP Is an Efficient Delivery Route to Reduce Infarct Volume and Promote Functional Recovery After Transient and Permanent Middle Cerebral Artery Occlusion. Frontiers in Endocrinology. 2021; 11: 585082.

[179] Brifault C, Gras M, Liot D, May V, Vaudry D, Wurtz O. Delayed pituitary adenylate cyclase-activating polypeptide delivery after brain stroke improves functional recovery by inducing $\mathrm{m} 2$ microglia/macrophage polarization. Stroke. 2015; 46: 520-528.

[180] Costigan M, Scholz J, Woolf CJ. Neuropathic Pain: a Maladaptive Response of the Nervous System to Damage. Annual Review of Neuroscience. 2009; 32: 1-32.

[181] Urits I, Adamian L, Fiocchi J, Hoyt D, Ernst C, Kaye AD, et al. Advances in the Understanding and Management of Chronic Pain in Multiple Sclerosis: a Comprehensive Review. Current Pain and Headache Reports. 2019; 23: 59.

[182] Romeo-Guitart D, Casas C. NeuroHeal Treatment Alleviates Neuropathic Pain and Enhances Sensory Axon Regeneration. Cells. 2020; 9: 808.

[183] Dickinson T, Fleetwood-Walker SM. VIP and PACAP: very important in pain? Trends in Pharmacological Sciences. 1999; 20: 324-329.

[184] Menorca RMG, Fussell TS, Elfar JC. Nerve physiology: mechanisms of injury and recovery. Hand Clinics. 2013; 29: 317-330.

[185] Missig G, Mei L, Vizzard MA, Braas KM, Waschek JA, Ressler $\mathrm{KJ}$, et al. Parabrachial Pituitary Adenylate Cyclase-Activating Polypeptide Activation of Amygdala Endosomal Extracellular Signal-Regulated Kinase Signaling Regulates the Emotional Component of Pain. Biological Psychiatry. 2017; 81: 671-682.

[186] Edvinsson L, Tajti J, Szalárdy L, Vécsei L. PACAP and its role in primary headaches. Journal of Headache and Pain. 2018; 19: 21.

[187] Mabuchi T, Shintani N, Matsumura S, Okuda-Ashitaka E, Hashimoto $\mathrm{H}$, Muratani $\mathrm{T}$, et al. Pituitary adenylate cyclaseactivating polypeptide is required for the development of spinal sensitization and induction of neuropathic pain. Journal of Neuroscience. 2004; 24: 7283-7291.

[188] Anapindi KDB, Yang N, Romanova EV, Rubakhin SS, Tipton A, Dripps I, et al. PACAP and other Neuropeptide Targets Link Chronic Migraine and Opioid-induced Hyperalgesia in Mouse Models. Molecular \& Cellular Proteomics. 2019; 18: 2447-2458.

[189] Waschek JA, Baca SM, Akerman S. PACAP and migraine headache: immunomodulation of neural circuits in autonomic ganglia and brain parenchyma. Journal of Headache and Pain. 2018; 19: 23.

[190] Takasaki I, Ogashi H, Okada T, Shimodaira A, Hayakawa D, Watanabe A, et al. Synthesis of a novel and potent small-molecule antagonist of PAC1 receptor for the treatment of neuropathic pain. European Journal of Medicinal Chemistry. 2020; 186: 111902 .

[191] Thomas Broome S, Musumeci G, Castorina A. Doxycycline and Minocycline Act as Positive Allosteric Modulators of the PAC1 Receptor and Induce Plasminogen Activators in RT4 Schwann Cells. Applied Sciences. 2021; 11: 7673.

[192] Baskozos G, Sandy-Hindmarch O, Clark AJ, Windsor K, Karlsson P, Weir GA, et al. Molecular and cellular correlates of human nerve regeneration: ADCYAP1/PACAP enhance nerve outgrowth. Brain. 2020; 143: 2009-2026.

[193] Dickinson T, Mitchell R, Robberecht P, Fleetwood-Walker SM. The role of VIP/PACAP receptor subtypes in spinal somatosensory processing in rats with an experimental peripheral mononeuropathy. Neuropharmacology. 1999; 38: 167-180.

[194] Karsan N, Goadsby PJ. Migraine Is More Than Just Headache: Is the Link to Chronic Fatigue and Mood Disorders Simply Due to Shared Biological Systems? Frontiers in Human Neuroscience. 2021; 15: 646692.

[195] Eigenbrodt AK, Ashina H, Khan S, Diener H, Mitsikostas DD, Sinclair AJ, et al. Diagnosis and management of migraine in ten steps. Nature Reviews Neurology. 2021; 17: 501-514.

[196] Deen M, Correnti E, Kamm K, Kelderman T, Papetti L, RubioBeltrán E, et al. Blocking CGRP in migraine patients - a review of pros and cons. Journal of Headache and Pain. 2017; 18: 96.

[197] Edvinsson L. Role of CGRP in Migraine. Handbook of Experimental Pharmacology. 2019; 255: 121-130.

[198] Edvinsson L, Haanes KA, Warfvinge K, Krause DN. CGRP as the target of new migraine therapies - successful translation from bench to clinic. Nature Reviews. Neurology. 2018; 14: 338-350.

[199] Syed AU, Koide M, Braas KM, May V, Wellman GC. Pituitary adenylate cyclase-activating polypeptide (PACAP) potently dilates middle meningeal arteries: implications for migraine. Journal of Molecular Neuroscience. 2012; 48: 574-583.

[200] Xu X, Liu L, Zhao L, Li B, Jing X, Qu Z, et al. Effect of Electroacupuncture on Hyperalgesia and Vasoactive Neurotransmitters in a Rat Model of Conscious Recurrent Migraine. EvidenceBased Complementary and Alternative Medicine. 2019; 2019: 9512875.

[201] Bertels Z, Pradhan AAA. Emerging Treatment Targets for Migraine and other Headaches. Headache. 2019; 59: 50-65.

[202] Tajti J, Tuka B, Botz B, Helyes Z, Vecsei L. Role of pituitary adenylate cyclase-activating polypeptide in nociception and $\mathrm{mi}-$ graine. CNS \& Neurological Disorders Drug Targets. 2015; 14: 540-553.

[203] Vollesen ALH, Amin FM, Ashina M. Targeted Pituitary Adenylate Cyclase-Activating Peptide Therapies for Migraine. Neurotherapeutics. 2018; 15: 371-376.

[204] Pellesi L, Al-Karagholi MA, De Icco R, Coskun H, Elbahi FA, Lopez-Lopez C, et al. Effect of Vasoactive Intestinal Polypeptide on Development of Migraine Headaches. American Medical Association Network Open. 2021; 4: e2118543.

[205] Goadsby P, Moreno-Ajona D, Villar-Martínez M. Emerging Targets for Migraine Treatment. Neurology India. 2021; 69: 98.

[206] Hoffmann J, Miller S, Martins-Oliveira M, Akerman S, Supronsinchai W, Sun $\mathrm{H}$, et al. PAC1 receptor blockade reduces central nociceptive activity: new approach for primary headache? Pain. 2020; 161: 1670-1681.

[207] Jansen-Olesen I, Hougaard Pedersen S. PACAP and its receptors in cranial arteries and mast cells. Journal of Headache and Pain. 2018; $19: 16$.

[208] Delgado M, Pozo D, Ganea D. The significance of vasoactive intestinal peptide in immunomodulation. Pharmacological Reviews. 2004; 56: 249-290.

[209] Raabe FJ, Slapakova L, Rossner MJ, Cantuti-Castelvetri L, Simons M, Falkai PG, et al. Oligodendrocytes as A New Therapeutic Target in Schizophrenia: From Histopathological Findings to Neuron-Oligodendrocyte Interaction. Cells. 2019; 8: 1496.

[210] Mitterauer BJ, Kofler-Westergren B. Possible effects of synaptic imbalances on oligodendrocyte-axonic interactions in schizophrenia: a hypothetical model. Frontiers in Psychiatry. 2011; 2: 15.

[211] Donkels C, Peters M, Fariña Núñez MT, Nakagawa JM, Kirsch $\mathrm{M}$, Vlachos A, et al. Oligodendrocyte lineage and myelination are compromised in the gray matter of focal cortical dysplasia type IIa. Epilepsia. 2020; 61: 171-184.

[212] Rodríguez-Cruces R, Concha L. White matter in temporal lobe epilepsy: clinico-pathological correlates of water diffusion abnormalities. Quantitative Imaging in Medicine and Surgery. 2015; 5: 264-278.

[213] Chen D, Huang Y, Shi Z, Li J, Zhang Y, Wang K, et al. Demyelinating processes in aging and stroke in the central nervous system and the prospect of treatment strategy. CNS Neuroscience \& Therapeutics. 2020; 26: 1219-1229.

[214] Khodanovich MY, Kisel AA, Akulov AE, Atochin DN, Kudabaeva MS, Glazacheva VY, et al. Quantitative assessment of demyelination in ischemic stroke in vivo using macromolecular proton fraction mapping. Journal of Cerebral Blood Flow \& Metabolism. 2018; 38: 919-931.

[215] Yang Y, Jalal FY, Thompson JF, Walker EJ, Candelario-Jalil $\mathrm{E}, \mathrm{Li} \mathrm{L}$, et al. Tissue inhibitor of metalloproteinases-3 mediates 
the death of immature oligodendrocytes via TNF-alpha/TACE in focal cerebral ischemia in mice. Journal of Neuroinflammation. 2011; 8: 108.

[216] Dejda A, Sokołowska P, Nowak JZ. Neuroprotective potential of three neuropeptides PACAP, VIP and PHI. Pharmacological Reports. 2005; 57: 307-320.

[217] Shioda S, Ohtaki H, Nakamachi T, Dohi K, Watanabe J, Nakajo $\mathrm{S}$, et al. Pleiotropic functions of PACAP in the CNS: neuroprotection and neurodevelopment. Annals of the New York Academy of Sciences. 2006; 1070: 550-560.

[218] Giunta S, Castorina A, Marzagalli R, Szychlinska MA, Pichler K, Mobasheri A, et al. Ameliorative effects of PACAP against cartilage degeneration. Morphological, immunohistochemical and biochemical evidence from in vivo and in vitro models of rat osteoarthritis. International Journal of Molecular Sciences. 2015; 16: 5922-5944.

[219] Lindén A, Hansson L, Andersson A, Palmqvist M, Arvidsson P,
Löfdahl C, et al. Bronchodilation by an inhaled VPAC(2) receptor agonist in patients with stable asthma. Thorax. 2003; 58: 217-221.

[220] Song S, Wang L, Li J, Huang X, Yu R. The allosteric modulation effects of doxycycline, minocycline, and their derivatives on the neuropeptide receptor PAC1-R. Acta Biochimica et Biophysica Sinica. 2019; 51: 627-637.

[221] Yu R, Li J, Lin Z, Ouyang Z, Huang X, Reglodi D, et al. TATtagging of VIP exerts positive allosteric modulation of the PAC1 receptor and enhances VIP neuroprotective effect in the MPTP mouse model of Parkinson's disease. Biochimica et Biophysica Acta. 2020; 1864: 129626.

[222] Yu R, Yang Y, Cui Z, Zheng L, Zeng Z, Zhang H. Novel peptide VIP-TAT with higher affinity for PAC1 inhibited scopolamine induced amnesia. Peptides. 2014; 60: 41-50.

[223] Liu D, Zhu M, Zhang Y, Diao Y. Crossing the blood-brain barrier with AAV vectors. Metabolic Brain Disease. 2021; 36: 45-52. 